\title{
AN OBSERVATIONAL STUDY OF 11 CASES OF CARTAP POISONING - A RARE POISONING
}

\author{
REKHA DAS ${ }^{1 *}$, SUMITA MOHANTY ${ }^{2}$, SANJAY KUMAR BEHERA ${ }^{3}$, RANJENDER KUMAR MEDIKONDA ${ }^{4}$
}

${ }^{1}$ Department of Anesthesia and Critical Care, AHRCC and ICU Consultant, Shanti Memorial Hospital, Cuttack, Odisha, India. ${ }^{2}$ Department of Anesthesia and Critical Care, AHRCC, Cuttack, Odisha, India. ${ }^{3}$ Department of Medicine, SCB Medical College, Cuttack, Odisha, India. ${ }^{4}$ Intensive Care Unit, Shanti Memorial Hospital, Cuttack, Odisha, India. Email: rekhadas2003@yahoo.co.in

Received: 05 June 2017, Revised and Accepted: 09 August 2017

ABSTRACT

Objective: Cartap hydrochloride poisoning is an uncommon poisoning encountered in India. The aim of this study was to assess the characteristics, severity, management, and outcome of patients with Cartap poisoning, treated with N-acetylcysteine (NAC) in intensive care unit (ICU) of a tertiary referral hospital.

Methods: This is a retrospective study where 11 cases of Cartap poisoning admitted to hospital ICU between 2011 and 2016 were identified from the case records. The demographic data, mode of ingestion, time to treat, ingested dose and severity of poisoning, presenting features, duration of mechanical ventilation (MV), dose of NAC used, complications, and outcome were noted.

Results: Patients were scored as moderate or severe cases of poisoning. Severe cases consumed $>10 \mathrm{~g}$, underwent gastric lavage $>4 \mathrm{hrs}$, and took Cartap concomitantly with alcohol or in empty stomach. Duration of MV varied from 68-94 hrs in severe cases and 12-48 hrs in moderate cases. Average dose of NAC in severe case was $11.19 \mathrm{~g}$ and moderate case was $8.89 \mathrm{~g}$. The most common presenting symptoms were vomiting, altered sensorium, and breathlessness. Severe cases had more complications, and the most common complication was hypotension followed by seizures. Survival was $100 \%$.

Conclusion: $50 \%$ of Cartap poisoning cases had good survival outcome. Severity of poisoning depends on amount of Cartap ingested, time taken for gastric lavage, and concomitant administration of alcohol. Duration of MV and dose of NAC and complications encountered correlates with the severity of poisoning.

Keywords: Cartap hydrochloride poisoning, Intensive care unit, N-acetylcysteine.

(c) 2017 The Authors. Published by Innovare Academic Sciences Pvt Ltd. This is an open access article under the CC BY license (http://creativecommons. org/licenses/by/4. 0/) DOI: http://dx.doi.org/10.22159/ajpcr.2017.v10i11.19069

\section{INTRODUCTION}

Cartap hydrochloride, an analog of nereistoxin, a neurotoxic substance derived from marine annelid lumbriconereis heteropoda [1], is a low toxicity insecticide commonly used in paddy fields and vegetable farming in Eastern India. It produces its toxic effects by affecting neuromuscular function [2]. It is described as high effectiveness, low residue pesticide; however, when severe can result in respiratory failure and death [3]. In India, it is available in two forms 4\% granular form and $50 \%$ water soluble powder form. Although a commonly used pesticide adequate literature regarding its treatment to toxic exposure or ingestion is lacking suggesting the rarity of such cases of poisoning. Cartap is a thiocarbamate and has a chemical formula $\mathrm{C}_{7} \mathrm{H}_{16} \mathrm{CIN}_{3} \mathrm{O}_{2} \mathrm{~S}_{2}$. Cartap inhibits the [3H]-ryanodine binding to the $\mathrm{Ca}^{2+}$ release channel in the sarcoplasmic reticulum in a dose-dependent manner, promotes extracellular $\mathrm{Ca}^{2+}$ influx, and induces release of internal $\mathrm{Ca}^{2+}$. It was hypothesized that Cartap-induced contracture was, to a minor extent, a result of inhibition of the sarcoplasmic reticulum $\mathrm{Ca}^{2+}$ pump protein $\mathrm{Ca}^{2+}$ ATPase. Inhibition of the ATPase would result in the unloading of calcium from the sarcoplasmic reticulum [4]. The WHO classifies it as moderately hazardous (Class II) technical grade active pesticides, LD50 mg/kg being $325 \mathrm{mg}$ [5] (in rats). The maximal acceptable daily intake (ADI) level is $0.05 \mathrm{mg} / \mathrm{kg}$ [6]. The USDA Foreign agricultural Service and Global Agricultural Information Network later stated that the ADI of Cartap is $0.1 \mathrm{mg} / \mathrm{kg}$ body weight [7], but unattended, delayed treatment, or in severe poisoning, death can occur. Mortality though low, early diagnosis, decontamination, appropriate life-saving supportive measures, and antidote treatment can ensure better survival. Keeping this in view, this study was undertaken with the primary aim to assess the factors that determined the severity of poisoning, and the secondary aim was to correlate the severity with the duration of mechanical ventilation (MV) and the dose of $\mathrm{N}$-acetylcysteine (NAC) used and outcome of patients.

\section{METHODS}

This is a retrospective study conducted in a referral hospital that receives around 150 cases of poisoning annually. Although rare in incidence with occasional published cases reports, a study was undertaken between 2011 and 2016 revealed 11 patients admitted to hospital with Cartap poisoning. The behavioral characteristics, management, and response to treatment in patients who had consumed Cartap were studied.

After obtaining institutional permission, all the poisoning cases in the medicolegal section of the medical record division of the hospital were searched for Cartap poisoning. Confidentiality was maintained by not disclosing the identity of the patients. Ethical approval was not taken as it was a retrospective study. Diagnosis was based on history, production of bottle; as our hospital had no provision of measuring blood level of Cartap. All cases of suspected or diagnosed pesticide poisoning were documented as per the protocol that included detailed history, name of poison, amount ingested, taken with food or empty stomach or with alcohol; any local or previous treatment received; reporting time to hospital (for gastric lavage); clinical presentation - nausea, vomiting, hiccups, tremulousness, salivation, dyspnea, seizures, mydriasis, unconsciousness, and respiratory failure; antidote name and dose used, intensive care unit (ICU) management, and duration of MV and outcome.

As per the treatment protocol of agricultural poisons, patients were given gastric lavage, clothes were removed, and a soap water bath 
was given. Initial assessment consisted of triaging the patient as mild, moderate, or severe cases of poisoning as per poison severity scoring (Table 1).

Initial resuscitation of all patients was done in the emergency unit. Patients presenting with GCS $<8$, convulsions, respiratory distress or low saturation, unstable hemodynamic, full stomach, and altered sensorium were intubated and mechanically ventilated. The antidote for Cartap poisoning used in our setup was NAC in a loading dose of $7.5 \mathrm{~g}$ intravenous (IV) followed by $350 \mathrm{mg}$ every 8 hourly till patients were conscious, oriented with improved respiratory functions. Blood pressure was maintained with IV fluids and if required noradrenaline was administered. Patients were sedated with nalbuphine and lorazepam as per the ICU protocol with daily awakening trials.

Initial laboratory investigations comprising complete blood count, electrolytes, blood gas, chest X-ray, liver, and renal profile were done and later followed up as warranted. Serum pseudocholinesterase was estimated to rule out mixed poisoning. All patients were closely monitored and followed up throughout their ICU stay. Assist volume control was initially used to mechanically ventilate the patients and weaned off later using pressure support and continuous positive airway pressure; when patients fulfilled satisfactory spontaneous awakening trials and spontaneous breathing trials they were extubated. Patients who had excessive endotracheal and oral secretions were infused with glycopyrrolate in dose that adequately dried up secretions. The findings were recorded in standard case pro forma and were presented as numbers, percentages, and mean \pm standard deviation. The data were finally analyzed using SPSS software version 20 . The $p<0.05$ was considered statistically significant.

\section{RESULTS}

Between 2011 and 2016, 11 cases of Cartap poisoning reported to the hospital. Patients were scored as moderate or severe cases of poisoning. Out of these (8/11), $72.72 \%$ were males (3/11) and $27.27 \%$ were females. The age of patients ranged from 23 to 56 year with the mean age being 43.70 year. All had consumed $50 \%$ Cartap with suicidal intention only. Patients were triaged as moderate or severe cases of poisoning as per Persson's poison severity score. Six cases were

Table 1: Persson et al. poisoning severity scores [8]

\begin{tabular}{ll}
\hline $\begin{array}{l}\text { Severity } \\
\text { grades score }\end{array}$ & Symptoms \\
\hline $\begin{array}{l}\text { None (0) } \\
\text { Minor (1) }\end{array}$ & $\begin{array}{l}\text { No symptoms or signs related to poisoning } \\
\text { Mild, transient, and spontaneously resolving } \\
\text { symptoms }\end{array}$ \\
Moderate (2) & Pronounced or prolonged symptoms \\
Severe (3) & Severe or life-threatening symptoms \\
Fatal (4) & Death \\
\hline
\end{tabular}

assessed as severe cases out of which, 3 had consumed 15-20 g and 10-15 g of Cartap. Three moderate cases and all severe cases underwent gastric lavage $>4 \mathrm{hrs}$. All severe cases took Cartap concomitantly with alcohol or in empty stomach. Duration of MV varied from 68 to $94 \mathrm{hrs}$ in severe cases and 12-48 hrs in moderate cases. Average dose of NAC in severe case was $11.19 \mathrm{~g}$ and moderate case was $8.89 \mathrm{~g}$. Survival was $100 \%$ (Table 2).

Most common and consistent presenting symptoms were vomiting, altered sensorium, and breathlessness. Hypotension in two case responded to fluids and in rest had to be topped up with inotropes. Allergic manifestation mostly in the form of rashes was self-limiting. Seizures in two patients persisted for 2-3 days requiring dual anticonvulsants (Table 3).

Severe cases had more complications and the most common complication was hypotension followed by seizures. Out of 6 cases of hypotension, 4 were in shock and 2 had prolonged hypotension. All responded to fluid challenge and inotrope support. Seizure was infrequent and generalized or focal in 3 cases and frequent generalized convulsion was witnessed in 2 cases. One patients in shock developed adult respiratory distress syndrome (ARDS), and one both ARDS and acute renal failure (ARF) (Table 4).

\section{DISCUSSION}

Cartap poisoning can mimic organophosphate (OP) or organochlorine poisoning and in many situation has been provisionally diagnosed as OP poison [9]. However, the situation in our case was different. We were handling with all cases of known Cartap poisoning which made our management easier. However, to rule out cases of mixed poisoning, we did a serum pseudocholinesterase in all cases which was found to be normal. All our patients had consumed 50\% powder form. Most of the published reports in India mentions ingestion of 50\% Cartap for suicidal poisoning. This form is used in India for control of diamondback moth in cabbage and cauliflower and is easily available. Although it is known to be of moderate toxicity, Gupta et al. says that it becomes toxic if consumed more than $75 \mathrm{ml}$ of solution containing $50 \%$ Cartap along with alcohol [10]; that is, $3.75 \mathrm{~g}$. All of our patients had consumed more than that. Although Lao in his initial studies says that Cartap is a safe compound with oral LD 50 in monkey being 100$200 \mathrm{mg} / \mathrm{kg}$ body wt [4], his later findings demonstrated diaphragmatic contracture and death of rabbit on ocular installation [3]

Most of studies on toxicology epidemiology is based on OP poisoning, the most common pesticide used for poisoning. It says that poisoning is more common among males being $60.46 \%$; the mean age group is $30.51 \pm 10.78$ year and the cause is a suicidal intention [11]. In our case, the poison being a rare poison, the figure is very small to comment on, but (8/11) $72.7 \%$ were males, mean age was 43.70 year (range - 2356 year), and the purpose was suicidal showing similar demographic

Table 2: Correlation of demography, dose of Cartap, and time of reporting with PSS score, duration of MV and dose of NAC, outcome

\begin{tabular}{|c|c|c|c|c|c|c|c|c|c|c|}
\hline Age & $\mathbf{M} / \mathbf{F}$ & Cause & How ingested & $\begin{array}{l}\text { Approximate } \\
\text { amount } \\
\text { ingested (g) }\end{array}$ & $\begin{array}{l}\text { Time to } \\
\text { gastric lavage } \\
\text { (h) }\end{array}$ & $\begin{array}{l}\text { Poisoning } \\
\text { severity score }\end{array}$ & $\begin{array}{l}\text { Duration } \\
\text { of MV (h) }\end{array}$ & $\begin{array}{l}\text { Dose of } \\
\text { NAC (g) }\end{array}$ & $\begin{array}{l}\text { Atropine } \\
\text { used }\end{array}$ & Outcome \\
\hline 50 & M & Suicidal & With food & $10-15$ & $<4$ & Moderate & 30 & 8.90 & No & Survived \\
\hline 45 & $\mathrm{~F}$ & Suicidal & With food & $5-10$ & $4-8$ & Moderate & 24 & 8.50 & No & Survived \\
\hline 40 & M & Suicidal & With alcohol & $15-20$ & $4-8$ & Severe & 90 & 11.40 & Yes & Survived \\
\hline 32 & $\mathrm{~F}$ & Suicidal & Empty stomach & $10-15$ & $>8$ & Severe & 90 & 11.70 & Yes & Survived \\
\hline 55 & M & Suicidal & With alcohol & $10-15$ & $4-8$ & Severe & 68 & 10.30 & Yes & Survived \\
\hline 56 & M & Suicidal & With food & $5-10$ & $<4$ & Moderate & 12 & 8.20 & No & Survived \\
\hline 50 & M & Suicidal & With food & $10-15$ & $4-8$ & Moderate & 42 & 9.25 & No & Survived \\
\hline 38 & $\mathrm{M}$ & Suicidal & With alcohol & $15-20$ & $>8$ & Severe & 94 & 12.06 & Yes & Survived \\
\hline 40 & M & Suicidal & Empty stomach & $15-20$ & $4-8$ & Severe & 84 & 11.00 & Yes & Survived \\
\hline 52 & M & Suicidal & With alcohol & $10-15$ & $4-8$ & Severe & 70 & 10.65 & No & Survived \\
\hline 23 & $\mathrm{~F}$ & Suicidal & With food & $10-15$ & $4-8$ & Moderate & 48 & 9.60 & No & Survived \\
\hline
\end{tabular}


Table 3: Presenting symptoms

\begin{tabular}{ll}
\hline Symptoms & Number of cases \\
\hline Vomiting & 11 \\
Drowsiness/altered sensorium & 11 \\
Breathlessness/hypoxemia & 10 \\
Hypotension & 8 \\
Rashes/allergic manifestations & 6 \\
Seizures & 5 \\
\hline
\end{tabular}

Table 4: Complications

\begin{tabular}{ll}
\hline Complication & Number of cases \\
\hline Seizures & 5 \\
Hypotension/shock & 6 \\
ARF & 1 \\
ARDS & 3 \\
\hline
\end{tabular}

ARDS: Adult respiratory distress syndrome, ARF: Acute renal failure

characteristics as of OP poisoning. Most of the cases were referred before $8 \mathrm{hrs}$ which shows the awareness of the people of rural Odisha and the good referral system made easy by introduction emergency ambulance.

We received all moderate-to-severe cases of poisoning. We presume that mild cases of this moderately hazardous poison were managed in local or government hospital out of ICU. Of the 11 cases, 6 were severe cases and 5 were moderate cases of poisoning. The severe cases had consumed either 15-20 g or 10-15 g of Cartap, and all had reported $4 \mathrm{hrs}$ after poison ingestion, and hence the treatment was started only after this. Before this only, a few underwent induced vomiting in the local hospitals. The concentration of Cartap is an important determining factor of the severity of poisoning and outcome [12]. This can be explained from the fact that the maximum quantity of poison ingested in our case was approximately $15-20 \mathrm{mg}$ which is more than the dose reported in Kurisaki et al. case and in both cases of Kurisaki et al. and Kuwahara et al., gastric lavage was also done early, but their patients died of multiorgan failure [13,14]. Percentage of Cartap in these cases was 75\%; in our case all patients had consumed $50 \%$ Cartap, probably the most common formulation available, thus justifying the concentration of poison as an important determining factor of mortality. Senthilkumaran observed that the food and alcohol enhanced the toxicity of Cartap [15]. Severe poisoning in our case was found in patients who had concomitantly consumed alcohol or ingested in empty stomach.

The shortest duration of MV was $12 \mathrm{hrs}$ and longest $94 \mathrm{hrs}$. In most of the published reports, patients were extubated in $48 \mathrm{hrs}$ [9]. In the only case report by Sodalagunta [16], patient was extubated on the $4^{\text {th }}$ day and the volume ingested was around $50 \mathrm{~g}$ which was much more than ours. Maximun dose of NAC given to our patient was $12 \mathrm{~g}$. Praveen Kumar and Sodalagunta in their cases have used $15 \mathrm{~g}$ of the same antidote which is quite comparable [16,17]. Monica et al. has used BAL in her patient. Sodium dimercaptopropanesulfonate and sodium dimercaptosuccinate are effective sulfhydryl antidotes for acute insecticides poisoning such as SCD [sodium ammonium dimethyl-2(propane-1, 3-dithiosulfate) monohydrate], nereistoxin, and Cartap in mouse models [18]. At present, the recommended antidotes for Cartap poisoning are $100-200 \mathrm{mg}$ of L-cysteine IV or $20-60 \mathrm{mg}$ of British Anti-Lewisite (dimercaprol; 2, 3-dimercapto propanol) intramuscular. It is possible that the effect of calcium binding of these antidotes is the mechanism of antagonizing the respiratory depression occurring in Cartap toxicity. Although there are yet no clear cut guidelines to the use of NAC, it has been used with good results $[17,19]$. Similar doses were used by Kalyaniwala et al. and their patient was weaned off from ventilator in $36 \mathrm{hrs}$ [20]. We preferred to use this dose and repeat it over the next 3-4 days depending on the severity of the case. We have not encountered any side effects in the dose used and all our patients recovered. Atropine was used in most patients where excessive secretion was encountered to prevent secondary infection.

Of the complications we encountered, the most common was hypotension. Six cases required inotrope support and one in shock developed both ARDS and ARF. He became oliguric but urination improved on day 3 and he was extubated on the $4^{\text {th }}$ day. Frequent generalized seizures responded to lorazepam followed by phenytoin sodium and if required levetiracetam. Both Kurisaki et al. and Kurisaki reported death of a 36-year-old male and a 50-year-old female, respectively, on the $5^{\text {th }}$ and $6^{\text {th }}$ day of ingestion of $75 \%$ Cartap $[13,14]$. In both cases, patient developed MOD (multiorgan failure). Both had received early gastric lavage but not any antidote. Although L-Cysteine and not NAC is the recommended antidote, we used NAC in our case due to easy availability, its successful administration in few published case reports and our familiarity of its use. All our patients with multiorgan failure recovered. In case of death due to MOD reported by Kurisaki et al. and Bunai et al., the blood concentration of Cartap was found to be $10.6 \mathrm{mcg} / \mathrm{ml} \mathrm{[13]} \mathrm{and} 11.5 \mathrm{mcg} / \mathrm{m} \mathrm{[21],} \mathrm{respectively,}$ whereas in Kiyota et al. case, where the patient survived after ingesting $50 \%$ Cartap the blood level was estimated to be $1.14 \mathrm{mcg} / \mathrm{ml}$ [22]. Singh et al. in a case study of paraquat poisoning, opined that different treatment modalities, namely, pulse therapy with cyclophosphamide and methylprednisolone, and hemoperfusion may be used to manage patient's condition. However, the patients may develop severe neutropenia and thrombocytopenia, but we had not found neutropenia or thrombocytopenia in our case series [23]. Khan et al. in their study revealed that females outnumbered males. Maximum numbers of cases were reported in the rainy season. Organophosphorus poisoning was observed to be the most common method. 21-30 year olds were most prone to suicidal poisoning, ascribed to their perturbation concerning the future issues [24]. Similarly studies on heavy metal poisoning have been done, but such studies with cartap is lacking [25].

We had no access to the measurement of blood level of Cartap which was the limitation of our study.

\section{CONCLUSION}

Unlike OP poisoning, Cartap poisoning is a rarer poisoning, probably due to its lesser availability. The reason is mostly suicidal. The age of ingestion is found to be varied but fall in the domain of productivity life. $50 \%$ of Cartap poisoning treated results in good survival outcome. NAC is associated with improved outcome of patients with Cartap poisoning. The severity of poisoning increases with the amount of Cartap ingested, time taken for gastric lavage, and when taken without food or with alcohol. Duration of MV, dose of NAC, and complications encountered correlates with the severity of poisoning. All patients recovered from complications. Atropine can be used to reduce increased secretions observed in severe cases of Cartap poisoning.

\section{REFERENCES}

1. Ray DE. Insecticides derived from plants and other organisms. Handbook of Insecticide Toxicology, Classes of Insecticide. Vol. 2. New York: Academic Press; 1991. p. 611-2.

2. Koyama K. Miscellaneous pesticides and fungicides. Jpn J Acute Med 1988;12:1457-61.

3. Liao JW, Pang VF, Jeng CR, Chang SK, Hwang JS, Wang SC. Susceptibility to cartap-induced lethal effect and diaphragmatic injury via ocular exposure in rabbits. Toxicology. 2003;5(192):139-48.

4. Liao JW, Kang JJ, Liu SH, Jeng CR, Cheng YW, Hu CM, et al. Effects of cartap on isolated mouse phrenic nerve diaphragm and its related mechanism. Toxicol Sci 2000;55(2):453-9.

5. International Programme of Chemical Safety. The WHO Recommended Classification of Pesticides by Hazard and Guidelines to Classification: 2009. Germany: World Health Organization; 2010.

6. International Programme of Chemical Safety. The WHO Recommended Classification of pesticides by Hazard and Guidelines to Classification 2000-2001. In: WHO, editors. WHO/PCA/0.1.5. Geneva: IOMC; 2002. p. 1-58.

7. Available from: http://www.gains.fas.usda.gov/maximum residue 
limits for pesticide in food China. [Last accessed on 2017 Apr 08].

8. Persson H, Sjöberg G, Haines J, Pronczuk de Garbino J. Poisoning severity score: Grading of acute poisoning. J Toxicol Clin Toxicol 1998;36(3):205-13.

9. Boorugu Hk, chrispal A. cartap hydrochloride poisoning: A clinical experience. Indian J Crit Care Med 2012;16(1):58-9.

10. Gupta M, Handa D, Chaturvedi A, Singh R, Lehl SS. Cartap poisoning: An unusual poisoning in North India. Int J Sci Rep 2015;1(1):99-101.

11. Ahmed SM, Das B, Nadeem A, Samal RK. Survival pattern in patients with acute organophosphate poisoning on mechanical ventilation: A retrospective intensive care unit-based study in a tertiary care teaching hospital. Indian J Anaesth 2014;58(1):11-7.

12. Raymond-Delpech V, Matsuda K, Sattelle BM, Rauh JJ, Sattelle DB. Ion channels: Molecular targets of neuroactive insecticides. Invert Neurosci 2005;5:119-33.

13. Kurisaki E, Kato N, Ishida T, Matsumoto A, Shinohara K, Hiraiwa K. Fatal human poisoning with Padan: A cartap-containing pesticide. Clin Toxicol (Phila) 2010;48(2):153-5.

14. Kuwahara H, Nakamura K, Morimura N, Shimizu M, Ishikawa J, Sugiyama MA, et al. Case of acute cartap poisoning. Kanto J Jpn Acute Med 2000;21:190-1.

15. Senthilkumaran $S$, Balamurgan N, Thirumalaikolundusubramanian $P$. Emerging epidemic of cartap self-poisoning in Southern India: A prospective observational study. J Gen Med 2007;19:54-5.

16. Sodalangunta MB, Sudulagunta SR, Khorram H, Sepehrar M. Cartap hydrochloride causing respiratory failure and seizures. Int J Med Pharm Case Rep 2015;5(2):1-4.
17. Kumar AS, Amalnath D, Dutta TK. Cartap poisoning: A rare case report. Indian J Crit Care Med 2011;15(4):233-5.

18. Cao BJ, Chen ZK, Chi ZQ. Antidotal effects of sulfhydryl compounds on acute poisonings by sodium ammonium dimethyl-2-(propane-1,3dithiosulfate) monohydrate, nereistoxin and cartap. Zhongguo Yao Li Xue Bao 1990;11(2):180-4.

19. Harsha T, Abhilesh KP, Hansdak SG. Cartap hydrochloride poisoning: A clnical experience with $\mathrm{N}$-acetyl cysteine therapy. J Med Sci Res 2013;4(1):30-1.

20. Kalyaniwala K, Abhilash KP, Victor PJ. Cartap hydrochloride poisoning. J Assoc Physicians India 2016;64(8):91-2.

21. Bunai Y, Akaza K, Tsujinaka M, Nakamura I, Nagai A, Takekoshi Y, et al. An autopsy case of fatal cartap poisoning. Res Pract Forensic Med 2001;44:111-4

22. Kiyota K, Honma M, Shigeta M, Miyake Y, Sakamoto T, Aruga T, et al. Cartap intoxication-pharmacokinetic analysis. Jpn J Toxicol 1994;7:263-70.

23. Ajit S, Rajesh V, Sonal S, Shastri B, Sarasavu K. Cyclophosphamide induced fatal cytopenia: A case of paraquat poisoning. Int J Pharm Pharm Sci 2016;8(10):296-7.

24. Khan P, Charry M, Kumar M, Nousheen B. A study on treatment pattern and outcomes of poisoning cases in a tertiary care and government district hospital. Int J Pharm Pharm Sci 2017;9(4):193-7.

25. Yashwant DS, Mohan CP, Adavirao V. Grey water farming of ladies finger and cluster beans-induces dietary toxicity?. Int J Curr Pharma ceutical Research 2017; 9(4): 201. 